\title{
Connecting laboratory behavior to field function through stable isotope analysis
}

Mael G Glon, Eric R Larson, Kevin L Pangle

Inherent difficulties of tracking and observing organisms in the field often leave researchers with no choice but to conduct behavioral experiments under laboratory settings. However, results of laboratory experiments do not always translate accurately to natural conditions. A fundamental challenge in ecology is therefore to scale up from small area and short-duration laboratory experiments to large areas and long durations over which ecological processes generally operate. In this study, we propose that stable isotope analysis may be a tool that can link laboratory behavioral observations to past field interactions or function of individual organisms. We conducted laboratory behavioral assays to measure dominance of invasive rusty crayfish, Orconectes rusticus[i], and used stable isotope analysis to hindcast trophic positions of these crayfish under preceding natural conditions. We hypothesized that more dominant crayfish in our assays would have higher trophic positions if dominance were related to competitive ability or willingness to pursue high-risk, high-reward prey. We did not find a relationship between crayfish dominance and trophic position, and therefore infer that laboratory dominance of crayfish may not necessarily relate to their ecology in the field. However, this is to our knowledge the first attempt to directly relate laboratory behavior to field performance via stable isotope analysis. We encourage future studies to continue to explore a possible link between laboratory and field behavior via stable isotope analysis, and propose several avenues to do so. 
2

3 Glon, Mael G. ${ }^{*}$, Larson, Eric R. ${ }^{\dagger}$ \& Pangle, Kevin L.*

4 *Department of Biology, Central Michigan University, Mount Pleasant, Michigan 48859

5 †epartment of Natural Resources and Environmental Sciences, University of Illinois, Urbana,

6 Illinois 61801

7

8 Correspondence:

9 Mael Glon

10 Brooks Hall 217

11 Central Michigan University

12 Mt Pleasant, MI 48859

13 glon1mg@cmich.edu

14

15

16

17

18

19

20

21

22

23 


\section{Abstract}

Inherent difficulties of tracking and observing organisms in the field often leave researchers with no choice but to conduct behavioral experiments under laboratory settings. However, results of laboratory experiments do not always translate accurately to natural conditions. A fundamental challenge in ecology is therefore to scale up from small area and short-duration laboratory experiments to large areas and long durations over which ecological processes generally operate. In this study, we propose that stable isotope analysis may be a tool that can link laboratory behavioral observations to past field interactions or function of individual organisms. We conducted laboratory behavioral assays to measure dominance of invasive rusty crayfish, Orconectes rusticus, and used stable isotope analysis to hindcast trophic positions of these crayfish under preceding natural conditions. We hypothesized that more dominant crayfish in our assays would have higher trophic positions if dominance were related to competitive ability or willingness to pursue high-risk, high-reward prey. We did not find a relationship between crayfish dominance and trophic position, and therefore infer that laboratory dominance of crayfish may not necessarily relate to their ecology in the field. However, this is to our knowledge the first attempt to directly relate laboratory behavior to field performance via stable isotope analysis. We encourage future studies to continue to explore a possible link between laboratory and field behavior via stable isotope analysis, and propose several avenues to do so.

Keywords: mixing model; dominance; agonistic assays; Orconectes rusticus; individual variation; invasive species 


\section{Introduction}

48

49

50

51

52

53

54

55

56

57

58

59

60

61

62

63

64

Animal behavior is inherently linked with the fields of ecology and evolution (Sih, Bell

\& Johnson, 2004; Réale, Reader \& Sol, 2007), and informs applications such as management of biological invasions (Sih et al., 2010). Owing to logistical difficulties inherent to tracking and observing organisms without interference in the field, however, many behavioral studies are conducted ex situ in a laboratory setting, where it may be difficult to extrapolate findings to natural conditions (Niemelä \& Dingemanse, 2014; Zavorka et al., 2015). For example, a suite of often-correlated behaviors including aggression, dominance, and boldness are believed to contribute to the success of some invasive over native species (Pintor, Sih \& Kerby, 2009; Hudina, Hock \& Žganec, 2014), but these same behaviors can be considerably muted in duration or intensity when observed in the field (Bergman \& Moore, 2003; Larson \& Magoulick, 2009). One of ecology's most fundamental challenges is scaling up from the type of small area and short duration experiments that are easy to conduct, to the larger areas and longer durations over which ecological processes often operate (Lodge et al., 1998). This same challenge applies when relating animal behaviors observed in the laboratory to ecological function and intra- or interspecific interactions in situ.

We propose here that linking laboratory behavioral observations to past field interactions or function of specific, individual organisms may be an overlooked application of stable isotope analysis. Stable isotopes of elements such as carbon and nitrogen are assimilated into tissues of consumer organisms relative to their diets in predictable and quantifiable ways (DeNiro \& Epstein, 1978; DeNiro \& Epstein, 1981). Importantly, stable isotopes of consumers equilibrate with those of their diets at different rates in different tissues, giving snapshots of ecological interactions that may scale from previous days to years (Buchheister \& Latour, 2010). Analyzing 
70 stable isotope ratios in organisms can provide ecological insights ranging from habitat use and

71 movement (Hobson, 1999) to trophic position (Post, 2002). For example, stable isotope analysis

72 of feathers has been used to make inferences about migration and habitat use of several species

73 of seabirds that spend winter months far from land and are therefore difficult to study during this

74 period (Phillips et al. 2009). In another example, Cherel et al. (2008) used stable isotope analysis

75 to identify the trophic position and diet composition of southern elephant seals (Mirounga

76 leonina) which forage at depths exceeding $1000 \mathrm{~m}$ and have largely digested their meals by the

77 time they return to land, precluding them from being studied using traditional methods (e.g.,

78 direct observation, gut content analysis). Similarly to how these and other studies have applied

79 stable isotope analysis to infer the influence of past behavior on current success of organisms, we

80 propose that stable isotope analysis could permit researchers to link laboratory interactions with

81 previous in situ habitat selection, movement, diet choice, or competitive interactions (Figure 1).

82 We conducted laboratory behavioral assays to measure individual dominance of invasive 83 rusty crayfish, Orconectes rusticus, and used stable isotope analysis to hindcast trophic position

84 of these crayfish under natural field conditions. We predicted that more dominant crayfish in the

85 behavioral assays would have higher trophic positions if dominance were related to competitive

86 ability in the field (e.g., ability to access high quality food such as macroinvertebrates; Roth,

87 Hein \& Vander Zanden, 2006) or willingness to pursue high-risk, high-reward prey such as fish

88 or other crayfish (Taylor \& Soucek, 2010). Alternatively, dominance and trophic position may

89 not be associated if laboratory behaviors are ultimately uninformative with respect to past

90 interactions of organisms. Numerous previous studies have used stable isotope analysis to infer

91 various in situ behaviors of organisms, such as habitat use and diet preferences (e.g., Hildebrand

92 et al., 1996; Rubenstein \& Hobson, 2004); however, our study is the first to our knowledge to 
93 seek a direct relationship for individual organisms between laboratory behaviors and field

94 function as determined by stable isotope analysis, and proposes the linkage of laboratory

95 behavioral assays and stable isotopes as a more common practice in the future.

96

97 Methods

Orconectes rusticus was introduced via the bait trade to the Laurentian Great Lakes circa

991960 and has negatively affected fish, macrophytes, and freshwater macroinvertebrates

100 (McCarthy et al., 2006; Peters et al. 2014). The invasion success of this crayfish has made it the 101 focal point of a large number of laboratory and field studies (e.g., Olsen et al., 1991; Wilson et $102 a l ., 2004)$ and hence, a useful organism to test for linkages between field and laboratory

103 behavior. We collected adult form II (reproductively inactive) male O. rusticus $(\mathrm{n}=40)$ by hand 104 on 16 June 2015 in the Chippewa River, Michigan $\left(43.5652^{\circ},-84.9183^{\circ}\right)$, where this species is 105 invasive. Because size influences the outcome of crayfish agonistic trials (Bergman \& Moore, 106 2003), we used crayfish within a carapace length range of 23.41 to $27.53 \mathrm{~mm}$, the smallest size 107 range for which we could collect 40 crayfish (see supplementary material for additional 108 morphometrics). Orconectes rusticus in this size range are small adults of the same age class 109 (Momot, 1967) and are therefore unlikely to have diets that differ from one another due to 110 ontogenetic shifts (Bondar et al., 2005; Larson, Olden \& Usio, 2010). Immediately following 111 collection, we placed crayfish in individual $16 \mathrm{oz}$. plastic containers filled to a depth of $2 \mathrm{~cm}$ 112 with river water and a rock for shelter.

113

114 Agonistic assays 
116 for at least one week to remove possible previous social experience that could influence

117 interactions (Seebacher \& Wilson, 2007). We conducted our experiment directly following

118 collection (17 June 2015 during daylight hours [07h19-18h59]), but believe that retaining any

119 existing dominance hierarchies from the field would increase the likelihood of a relationship

120 between laboratory behaviors and previous field function.

121 We conducted three rounds of twenty, randomized paired assays, with each crayfish

122 fighting one opponent per round (no interactions between individuals were repeated). In order to

123 track individual crayfish, we randomly assigned each crayfish a number from 1 to 40 , which we

124 wrote on the dorsal side of its carapace using a permanent marker. Prior to the start of each

125 assay, crayfish were placed on opposite sides of a separator in a 191 bucket and allowed to

126 acclimate for 15 minutes. We then removed the separator and allowed the crayfish to interact for

12710 minutes. During each assay, we scored each of the two crayfish individually based on the

128 interactions that took place when they were within one body length of each other. All agonistic

129 assays were watched and scored in real time by a single observer to ensure consistency in

130 scoring. The agonistic assays within each of the three rounds were held in a random order, and

131 the observer had no knowledge of totaled crayfish scores from previous rounds so as to avoid

132 bias.

133 The scoring system we used has possible point values ranging from -2 (fast retreat) to 5

134 (unrestrained fighting) and is based on the ethogram modified from Bruski \& Dunham (1987;

135 Table 1). Following each assay, the participating crayfish were returned to their original holding 136 container. We then rinsed buckets and refilled them to a depth of $5 \mathrm{~cm}$ with fresh water from the 137 Chippewa River $\left(18-20^{\circ} \mathrm{C}\right)$. At the conclusion of all assays, crayfish were placed in individual, 
138 labelled bags and euthanized by freezing at $-17.8^{\circ} \mathrm{C}$. We calculated the dominance score of each

139 crayfish by first summing its scores from each round, then taking the mean of the three resulting

140 scores.

141

142 Stable isotope analysis

143 Stable isotope analysis is a technique based on the principle that the ratios of heavy to

144 light isotopes in the tissues of consumers reflect those of their diets in a predictable way (DeNiro

145 \& Epstein, 1978; DeNiro \& Epstein, 1981). Stable isotope analysis generally entails drying and

146 homogenizing tissue or whole-body samples of focal organisms, then using a mass spectrometer

147 coupled with an elemental analyzer to determine their constituent ratios of heavy to light isotopes

148 (i.e., $\left.R_{\text {sample }}\right)$. The isotope signatures of samples $\left(\delta^{\mathrm{x}}\right)$, expressed in per mille $(\%)$, are then

149 calculated as $\delta^{\mathrm{x}}=\left(\left(\frac{\mathrm{R}_{\text {sample }}}{\mathrm{R}_{\text {standard }}}\right)-1\right) * 1000$ where $\mathrm{R}_{\text {standard }}$ is the isotopic ratio of a standard (e.g.,

150 Vienna PeeDee Belemnite for carbon; air for nitrogen). This technique is often used to study the

151 roles and interactions of organisms in ecosystems, particularly as related to trophic position and

152 diet composition (Vander Zanden \& Rasmussen, 1999; Post, 2002), but patterns of stable isotope

153 spatial structure can also be applied to study organismal movement and habitat use (Hobson,

154 1999; Seminoff et al., 2012).

155 In freshwater ecology, the most commonly used stable isotopes have been carbon and

156 nitrogen (denoted $\delta^{13} \mathrm{C}$ and $\delta^{15} \mathrm{~N}$, respectively). Specifically, $\delta^{13} \mathrm{C}$ provides a tracer of energy

157 source origin because it is fixed by primary producers at photosynthesis and is well-conserved up

158 food chains with little change in value with each increasing trophic level (termed discrimination;

159 generally 0-1\%o; Fry \& Sherr, 1984). Common sources of primary productivity in freshwater

160 habitats that can often be distinguished by analyzing $\delta^{13} \mathrm{C}$ include a benthic algal pathway, an 
161 open water phytoplankton pathway, and an allochthonous terrestrial detrital pathway; the

162 importance of these pathways to consumers can vary depending on habitat attributes (Dekar,

163 Magoulick \& Huxel, 2009; Francis et al., 2011). In contrast to $\delta^{13} \mathrm{C}, \delta^{15} \mathrm{~N}$ can be used to estimate

164 trophic position of organisms as it generally increases or discriminates at a predictable $3.4 \pm 1.1$

$165 \%$ with each increasing trophic level, from primary producers to primary, secondary, and tertiary

166 consumers (Minagawa \& Wada, 1984). In some cases, $\delta^{15} \mathrm{~N}$ can be used alone to infer trophic

167 position of organisms; however, this is not the case if different sources of primary productivity

168 used by a consumer are depleted or enriched in $\delta^{15} \mathrm{~N}$ relative to each other (Vander Zanden \&

169 Rasmussen, 1999; Post, 2002; Figure 2). Under these circumstances, mixing models can be used

170 to estimate contributions of different energy pathways to consumers, and subsequently correct

171 for differences in their $\delta^{15} \mathrm{~N}$ enrichment while calculating trophic position of consumers (Post,

172 2002).

173 For this experiment, we collected snails (Elimia livescens; $\mathrm{n}=45$ ) and mussels (Elliptio

174 dilatata; $\mathrm{n}=5$ ) in the same stretch of the Chippewa River and on the same date as our crayfish

175 (see above), which we froze at $-17.8^{\circ} \mathrm{C}$, to be used as primary consumer endpoints in a two end-

176 member stable isotope mixing model related to calculating trophic position of crayfish. We chose

177 these specific organisms as they are reliable primary consumers (i.e., trophic position $=2$ ) whose

178 relatively large size and long lives make their isotopic signatures more robust to spatial and

179 temporal variation than those of primary producers (Cabana \& Rasmussen, 1996; Post, 2002).

180 Specifically, we used snails to represent the isotopic signature of algal-based primary production

181 and filter-feeding mussels as an additional endpoint to represent a broad range of other potential

182 sources of primary production in lotic systems (e.g., benthic algae, terrestrial detritus, and 
183 phytoplankton from upstream lentic systems; Raikow \& Hamilton, 2001; Cole \& Solomon, 184 2002).

185 We dissected crayfish for abdominal muscle, snails for whole body without shell, and 186 mussels for foot muscle. We dried samples at $60^{\circ} \mathrm{C}$ for $24 \mathrm{~h}$, homogenized them in an ethanol187 rinsed mortar and pestle, then weighed and encapsulated aliquots weighing $0.64 \pm .04 \mathrm{mg}$ of each 188 sample into tin capsules. We sent these samples to the Stable Isotope Mass Spectrometry Lab at 189 the University of Florida for analysis on a Micromass Prism II isotope ratio mass spectrometer 190 coupled with an elemental analyzer. Two internationally recognized standards (l-glutamic acids),

191 USGS40 (mean \pm standard deviation $\delta^{13} \mathrm{C},-26.39 \% \pm 0.11 ; \delta^{15} \mathrm{~N},-4.53 \% \pm 0.12$; measured 192 repeatedly for calibration) and USGS41 $\left(\delta^{13} \mathrm{C}, 47.57 \%\right.$; $\delta^{15} \mathrm{~N}, 37.36 \%$; measured once as a 193 check standard), were measured during the analysis to ensure precision. We calculated the relative contribution of the primary productivity represented by snails

195 (SPP) to our crayfish as SPP $=\frac{\left(\delta^{13} \mathrm{C}_{\text {crayfish }}-\delta^{13} \mathrm{C}_{\text {mussel }}\right)}{\left(\delta^{13} \mathrm{C}_{\text {snail }}-\delta^{13} \mathrm{C}_{\text {mussel }}\right)} * 100$, where $\delta^{13} \mathrm{C}_{\text {crayfish }}$ is the $\delta^{13} \mathrm{C}$ of each 196 crayfish, $\delta^{13} C_{\text {mussel }}$ is the mean $\delta^{13} \mathrm{C}$ of our mussel samples and $\delta^{13} \mathrm{C}_{\text {snail }}$ is the mean $\delta^{13} \mathrm{C}$ of our 197 snail samples. We then calculated the relative contribution of the primary productivity 198 represented by mussels (MPP) as MPP $=100-$ SPP. Lastly, we calculated the trophic position 199 (TP) of our crayfish as TP $=2+\frac{\delta^{15} \mathrm{~N}_{\text {crayfish }}-\left(\delta^{15} \mathrm{~N}_{\text {snail }} * \frac{\mathrm{sPP}}{100}+\delta^{15} \mathrm{~N}_{\text {mussel }}\left(\frac{\mathrm{MPP}}{100}\right)\right)}{\Delta^{15} \mathrm{~N}}$, where $\delta^{15} \mathrm{~N}_{\text {crayfish }}$ is the $\delta^{15} \mathrm{~N}$ 200 of each crayfish, $\delta^{15} \mathrm{~N}_{\text {snail }}$ is the mean $\delta^{15} \mathrm{~N}$ of the snails, $\delta^{15} \mathrm{~N}_{\text {mussel }}$ is the mean $\delta^{15} \mathrm{~N}$ of the 201 mussels, and $\Delta^{15} \mathrm{~N}$ is a trophic discrimination factor of 3.4 (Minagawa \& Wada, 1984). 202 203 Statistical analysis 
205 and calculated trophic positions of our crayfish. Additionally, we performed several linear

206 regressions controlling for the effect of body size on crayfish dominance by using residuals, as

207 well as a linear regression testing for a relationship between mean dominance score and

208 unaltered $\delta^{15} \mathrm{~N}$ signatures rather than calculated trophic position (supplementary material). All

209 analyses were conducted using the R statistical program (R Core Team, 2014).

210

\section{Results}

Snails were enriched in $\delta^{13} \mathrm{C}$ (mean \pm standard deviation; $-27.9 \pm 0.9 \%$; Figure 2 )

213 relative to mussels $\left(-32.0 \pm 0.2 \%\right.$ ). The relatively depleted $\delta^{13} \mathrm{C}$ signature of the mussels likely

214 reflects utilization of either phytoplankton or allochthonous terrestrial detritus as food resources,

215 relative to the generally more ${ }^{13} \mathrm{C}$ enriched benthic algal pathway (Raikow \& Hamilton, 2001;

216 Cole \& Solomon, 2002). The percent reliance of crayfish (mean \pm standard deviation) on the

217 snail pathway was $67.6 \pm 11.3 \%$, relative to $32.4 \pm 11.3 \%$ on the mussel pathway, indicating

218 that most of these crayfish relied twice as much on the snail than mussel resource pathway (see

219 supplementary material for analysis of the relationship between percent reliance of crayfish on

220 the snail primary production pathway and dominance scores). Our mixing model calculations

221 identified reliance of our crayfish on food resources from these two isotopically distinct

222 pathways, allowing us to correct for the relatively depleted $\delta^{15} \mathrm{~N}$ signature of mussels with

223 respect to the crayfish trophic position. Trophic positions of crayfish ranged from 2.1 to 2.6 with

224 a mean of $2.3 \pm 0.1$, suggesting a range of foraging behaviors from high reliance on primary

225 producers like benthic algae (i.e., trophic position $=2$ ) to some predation on primary consumers

226 like snails (i.e., trophic position $=3$ ). 
$228 \min ,-23.33$; max, 80.67). We did not find a significant relationship between dominance and

229 trophic position $\left(\mathrm{y}=0.0005 \mathrm{x}+2.32, \mathrm{R}^{2}=0.013, \mathrm{~F}_{1,38}=0.51, p=0.48\right.$; Figure 3$)$. Our additional

230 analyses accounting for the role of body size on both dominance and trophic position, as well as

231 those using an alternative measure of trophic position, did not affect our conclusion that there is

232 no association between dominance and trophic position (supplementary material).

\section{Discussion}

235 We failed to find a relationship between crayfish dominance and trophic position. We

236 therefore infer that laboratory dominance among these organisms may not necessarily relate to

237 their dietary preferences in the field, despite our prediction that more dominant crayfish should

238 be more likely than subordinate crayfish to compete successfully for high quality food or to

239 pursue high-risk, high-reward prey (Roth, Hein \& Vander Zanden, 2006; Taylor \& Soucek,

240 2010). However, this is to our knowledge the first attempt to relate laboratory behavior to field

241 performance via stable isotope analysis; therefore, more studies are warranted to further explore

242 linkages between these two techniques in light of possible sources of discord.

243 For example, other behaviors may correlate better with trophic position than dominance

244 in paired agonistic assays. Dominance assays may instead be more informative with respect to

245 acquisition of shelter to avoid fish predation or fitness via sexual selection (Garvey, Stein \&

246 Thomas, 1994; Bergman \& Moore, 2003), whereas trophic position in the field might correlate

247 better with other measures of laboratory behavior, such as boldness. However, dominance and

248 boldness have been observed to correlate as "behavioral syndromes" in crayfish (Pintor, Sih \&

249 Kerby, 2009), and we would therefore expect boldness and dominance to both correlate with 
250 trophic position. It is also possible that there is a temporal disconnect between our analysis of

251 crayfish abdominal tissue, which has an isotopic half-life of approximately 20-30 days (Glon,

252 Larson \& Pangle, 2016), and the social memory of our crayfish, which is thought to last from 60

253 minutes to one week (Bergman et al., 2003). Use of a tissue with a faster turnover rate (e.g.,

254 haemolymph) may better reflect the most recent in situ behavior of crayfish. Further, male

255 crayfish of the family Cambaridae cycle between a reproductively inactive form II and an active

256 form I stage. We used form II male crayfish, which are typically less aggressive than crayfish in

257 form I (Bergman et al., 2003). Replicating our experiment with form I individuals might alter the

258 results of agonistic assays and their relationship to trophic position.

259 Lastly, a possible limitation of our study was our relatively small sample size $(n=40$;

260 Galván, Sweeting \& Reid, 2010). In order to determine if our lack of a significant relationship

261 stemmed from low power, we conducted power analyses using the pwr package in R (Champely,

262 2015). We found that for our observed effect size (0.013; calculated as $\frac{\mathrm{R}^{2}}{1-\mathrm{R}^{2}}$ [Cohen, 1988]) and

263 an alpha of 0.05 and conventional power of 0.80 , we would have required 605 crayfish replicates

264 to observe statistical significance. Conversely, for an alpha of 0.05 and power of 0.80 , the

265 smallest effect size we would have detected as significant with 40 crayfish replicates was 0.21

$266\left(\mathrm{R}^{2}=0.173\right)$. We therefore conclude that although the effect size observed here could only be

267 detected as statistically significant with an uncommonly high level of replication (perhaps

268 dismissed as statistical significance without biological significance; Nakagawa \& Cuthill, 2007),

269 our level of replication was adequate to find significant relatively weak effect sizes down to an

$270 \quad \mathrm{R}^{2}=0.173$.

271 Although our study failed to find an association between crayfish dominance and stable

272 isotope-estimated trophic position, we believe that there are many unexplored and promising 
273 avenues to combine behavioral and isotope ecology in order to learn more about how behavior

274 observed in laboratories corresponds with movement and organismal interactions in the field.

275 Laboratory experiments and stable isotope analyses have both separately been used to explore

276 the "ecology of individuals" or variation within populations and species (Bolnick et al., 2003;

277 Niemelä \& Dingemanse, 2014; Zavorka et al., 2015), yet to our knowledge, researchers have not

278 previously combined or compared these approaches for the same organisms. For example, stable

279 isotope analysis and behavioral assays could be combined to together evaluate whether range

280 expansion of invasive species is being driven by subordinate individuals with low trophic

281 positions that are excluded from core habitats by dominant intraspecific competitors, or instead

282 bold or aggressive individuals with high trophic positions that are inclined to disperse (Hudina,

283 Hock \& Žganec, 2014). Further, where distinct stable isotope signatures exist over habitat

284 gradients (Hobson, 1999), researchers could infer whether individuals with or without dispersal-

285 related behaviors observed in the laboratory were actually recent arrivals or longstanding

286 residents of their collection locations. We encourage future studies to further explore the possible

287 insights gained by linking laboratory behavior with field function through stable isotope analysis,

288 as doing so could contribute meaningfully to an array of ecological and evolutionary questions.

\section{Acknowledgements}

291 We thank Matt Cooper, Jason Curtis, and Jim Student for use of equipment and facilities;

292 Heather Dame and Sara Thoma for help with crayfish collection; and Daelyn Woolnough for

293 assistance with mollusk identification. We also thank Axios Review for their assistance in

294 preparing this manuscript for publication, as well as three reviewers that provided us with helpful 295 feedback. 


\section{References}

298

299 1. Bergman DA, Kozlowski CP, McIntyre JC, Huber R, Daws AG, Moore PA. 2003 Temporal dynamics and communication of winner-effects in the crayfish, Orconectes rusticus. Behavior 140, 805-825. (doi:10.2307/4536060?ref=no-Xroute:f160d35c38bcbb64283778096994b59d)

2. Bergman DA, Moore PA. 2003 Field observations of intraspecific agonistic behavior of two crayfish species. The Biological Bulletin 205, 26-35. (doi:10.2307/1543442) The American Naturalist 161, 1-28. (doi: 10.1086/343878)

4. Bondar CA, Bottriell K, Zeron K, Richardson JS. 2005 Does trophic position of the omnivorous signal crayfish (Pacifastacus leniusculus) in a stream food web vary with life history stage or density? Canadian Journal of Fisheries and Aquatic Sciences 62, 26322639. (doi: 10.1139/f05-167) (doi:10.2307/4534636?ref=no-X-route:f30d21b77345a336a829ecff77a13880)

6. Buchheister A, Latour RJ. 2010 Turnover and fractionation of carbon and nitrogen stable 5. Bruski CA, Dunham DW. 1987 The importance of vision in agonistic communication of isotopes in tissues of a migratory coastal predator, summer flounder (Paralichthys dentatus). Canadian Journal of Fisheries and Aquatic Sciences 67, 445-461. (doi:10.1139/F09-196) 
319 7. Cabana G, Rasmussen JB. 1996 Comparison of aquatic food chains using nitrogen

320 isotopes. Proceedings of the National Academy of Sciences of the United States of

$321 \quad$ America 93, 10844-10847.

322 8. Champely S. 2015 pwr: basic functions for power analysis. R package version 1.1-3.

323 http://CRAN.R-project.org/package=pwr.

324 9. Cherel Y, Kernaléguen L, Richard P, Guinet C. 2008 Whisker isotopic signature depicts 325 migration patterns and multi-year intra- and inter-individual foraging strategies in fur seals. Biology Letters 5, 830-832.

327 10. Cohen, J. 1988 Statistical power analysis for the behavioral sciences. $2^{\text {nd }}$ edn. Hillsdale, $328 \quad$ New Jersey: Lawrence Erlbaum.

329 11. Cole JJ, Solomon CT. 2012 Terrestrial support of zebra mussels and the Hudson River 330 food web: A multi-isotope, Bayesian analysis. Limnology and Oceanography. 57, 1802331 1815. (doi:10.4319/1o.2012.57.6.1802)

332 12. Dekar MP, Magoulick DD, Huxel GR. 2009 Shifts in the trophic base of intermittent stream food webs. Hydrobiologia 635, 263-277. (doi:10.1007/s10750-009-9919-1)

13. DeNiro MJ, Epstein S. 1978 Influence of diet on the distribution of carbon isotopes in animals. Geochimica et Cosmochimica Acta 42, 495-506. (doi:10.1016/00167037(78)90199-0)

14. DeNiro MJ, Epstein S. 1981 Influence of diet on the distribution of nitrogen isotopes in animals. Geochimica et Cosmochimica Acta 45, 341-351. (doi:10.1016/00167037(81)90244-1) 
340 15. Francis TB, Schindler DE, Holtgrieve GW, Larson ER, Scheuerell MD, Semmens BX,

341 Ward EJ. 2011 Habitat structure determines resource use by zooplankton in temperate

342 lakes. Ecology Letters 14, 364-372. (doi:10.1111/j.1461-0248.2011.01597.x.)

343 16. Fry B, Sherr EB. $1984 \Delta^{13}$ C measurements as indicators of carbon flow in marine and

344 freshwater ecosystems. Contributions in Marine Science 27, 13-47.

345 (doi:10.1007\%2F978-1-4612-3498-2_12)

346 17. Galván DE, Sweeting CJ, Reid WDK. 2010 Power of stable isotope techniques to detect

347 size-based feeding in marine fishes. Marine Ecology Progress Series 407, 271-278. (doi:

$348 \quad 10.3354 / \operatorname{meps} 08528)$

349 18. Garvey JE, Stein RA, Thomas HM. 1994 Assessing how fish predation and interspecific

$350 \quad$ prey competition influence a crayfish assemblage. Ecology 75, 532-547. (doi:

$351 \quad 10.2307 / 1939556)$

352 19. Glon MG, Larson ER, Pangle KL. 2016 Comparison of ${ }^{13} \mathrm{C}$ and ${ }^{15} \mathrm{~N}$ Discrimination

353 Factors and Turnover Rates between Congeneric Crayfish Orconectes rusticus and $O$.

354 virilis (Decapoda, Cambaridae). Hydrobiologia 768, 51-61. (doi:10.1007/s10750-015-

$355 \quad 2527-3)$

356 20. Hildebrand GV, Farley SD, Robbins CT, Hanley TA, Titus K, Servheen C. 1996.

357 Canadian Journal of Zoology 74, 2080-2088. (doi: 10.1139/z96-236)

358 21. Hobson KA. 1999 Tracing origins and migration of wildlife using stable isotopes: a

359 review. Oecologia 120, 314-326. (doi:10.2307/4222394?ref=no-X-

360 route:da43d6d4b72fe6eabb7763bede305448)

361 22. Hudina S, Hock K, Žganec K. 2014 The role of aggression in range expansion and

362 biological invasions. Current Zoology 60, 401-409. 
363 23. Larson ER, Magoulick DD. 2009 Does juvenile competition explain displacement of a

364 native crayfish by an introduced crayfish? Biological Invasions 11, 725-735. (doi: http://10.1007/s10530-008-9286-2)

24. Larson ER, Olden JD, Usio N. 2010 Decoupled conservatism of Grinnellian and Eltonian niches in an invasive arthropod. Ecosphere 1, 1-13. (doi: http://10.1890/ES10-00053.1)

25. Lodge DM, Stein RA, Brown KM, Covich AP, Bronmark C, Garvey JE, Klosiewskt SP. 1998 Predicting impact of freshwater exotic species on native biodiversity: Challenges in spatial scaling. Australian Journal of Ecology 23, 53-67. (doi:10.1111/j.14429993.1998.tb00705.x) communities. Freshwater Biology 51, 224-235. (doi:10.1111/j.1365-2427.2005.01485.x)

27. Minagawa M, Wada E. 1984 Stepwise enrichment of ${ }^{15} \mathrm{~N}$ along food chains: Further 26. McCarthy JM, Hein CL, Olden JD, Vander Zander JM. 2006 Coupling long-term studies with meta-analysis to investigate impacts of non-native crayfish on zoobenthic evidence and the relation between $\delta^{15} \mathrm{~N}$ and animal age. Geochimica et Cosmochimica Acta 48, 1135-1140. (doi:10.1016/0016-7037(84)90204-7) virilis, in a marl lake. American Midland Naturalist 78, 55-81. (doi: 10.2307/2423370) a practical guide for biologists. Biological Reviews 82, 591-605. (doi: 10.1111/j.1469185X.2007.00027.x)

30. Niemelä PT, Dingemanse NJ. 2014 Artificial environments and the study of 'adaptive' personalities. Trends in Ecology and Evolution 29, 245-247. (doi:10.1016/j.tree.2014.02.007) 
31. Olsen TM, Lodge DM, Capelli GM, Houlihan RJ. 1991 Mechanisms of impact of an introduced crayfish (Orconectes rusticus) on littoral congeners, snails, and macrophytes. Canadian Journal of Fisheries and Aquatic Sciences 48, 1853-1861. (doi: 10.1139/f91219)

32. Phillips RA, Bearhop S, Mcgill RA, Dawson DA. 2009 Stable isotopes reveal individual variation in migration strategies and habitat preferences in a suite of seabirds during the nonbreeding period. Oecologia 160, 795-806.

33. Peters JA, Cooper MJ, Creque SM, Kornis MS, Maxted JT, Perry WL, Schueler FW, Simon TP, Taylor CA, Thoma RF, Uzarski DG, Lodge DM. 2014 Historical changes and

34. Pintor LM, Sih A, Kerby JL. 2009 Behavioral correlations provide a mechanism for explaining high invader densities and increased impacts on native prey. Ecology 90, 581587. (doi:10.1890/08-0552.1)

35. Post DM. 2002 Using stable isotopes to estimate trophic position: models, methods, and assumptions. Ecology 83, 703-718. (doi:10.1890/00129658(2002)083[0703:USITET]2.0.CO;2) Foundation for Statistical Computing, Vienna, Austria. URL http://www.R-project.org/.

37. Raikow DF, Hamilton SK. 2001 Bivalve diets in a Midwestern U.S. stream: A stable isotope enrichment study. Limnology and Oceanography 46, 514-422. (doi:10.4319/lo.2001.46.3.0514) 
408 38. Réale D, Reader SM, Sol D, McDougall PT, Dingemanse NJ. 2007 Integrating animal

409

410

411

412

413

414

415

416

417

418

419

420

421

422

423

424

425

426

427

428

429 temperament within ecology and evolution. Biological Review 82, 291-318. (doi:10.1111/j.1469-185X.2007.00010.x)

39. Roth BM, Hein CL, Vander Zanden MJ. 2006 Using bioenergetics and stable isotopes to assess the trophic role of rusty crayfish (Orconectes rusticus) in lake littoral zones. Canadian Journal of Fisheries and Aquatic Sciences 63, 335-344. (doi:10.1139/f05-217)

40. Rubenstein DR, Hobson KA. 2004 From birds to butterflies: animal movement patterns and stable isotopes. Trends in Ecology \& Evolution 5, 256-263. (doi:10.1016/j.tree.2004.03.017)

41. Seebacher F, Wilson RS. 2007 Individual recognition in crayfish (Cherax dispar): the roles of strength and experience in deciding aggressive encounters. Biology Letters $\mathbf{3}$, 471-474. (doi:10.1098/rsbl.2007.0289)

42. Seminoff JA, Benson SR, Arthur KE, Eguchi T, Dutton PH, Tapilatu RF, Popp BN. 2012 Stable isotope tracking of endangered sea turtles: validation with satellite telemetry and $\delta^{15} \mathrm{~N}$ analysis of amino acids. PLOS One 7, e37403. (doi:10.1371/journal.pone.0037403) 43. Sih A, Bell A, Johnson JC. 2004 Behavioral syndromes: an ecological and evolutionary overview. Trends in Ecology \& Evolution 19, 372-378. (doi:10.1016/j.tree.2004.04.009)

44. Sih A, Bolnick DI, Luttbeg B, Orrock JL, Peacor SD, Pintor LM, Preisser E, Rehage JS, Vonesh JR. 2010 Predator-prey naïveté, antipredator behavior, and the ecology of predator invasions. Oikos 119, 610-621. (doi:10.1111/j.1600-0706.2009.18039.x)

45. Taylor CA, Soucek DJ. 2010 Re-examining the Importance of Fish in the Diets of Stream-dwelling Crayfishes: Implications for Food Web Analyses and Conservation. The 
430

431

432

433

434

435

436

437

438

439

440

441

442

443

444

445

446

447

449

450

451

452

50

51

448

American Midland Naturalist 163, 280-293. (doi:10.2307/40730925?ref=no-x-

route:9c05d428aee4e32a102983467464740d)

46. Vander Zanden MJ, Rasmussen JB. 1999 Primary consumer $\delta^{13} \mathrm{C}$ and $\delta^{15} \mathrm{~N}$ and the trophic position of aquatic consumers. Ecology 80, 1395-1404. (doi:10.1890/00129658(1999)080[1395:PCCANA]2.0.CO;2)

47. Wilson KA, Magnuson JJ, Lodge DM, Hill AM, Kratz TK, Perry WL, Willis TV. 2004 A long-term rusty crayfish (Orconectes rusticus) invasion: dispersal patterns and community change in a north temperate lake. Canadian Journal of Fisheries and Aquatic Sciences 61, 2255-2266. (doi: 10.1139/f04-170)

48. Zavorka L, Aldven D, Naslund J, Hojesjo J, Johnsson JI. 2015 Linking lab activity with growth and movement in the wild: explaining pace-of-life in a trout stream. Behavioral Ecology 26, 877-884. (doi:10.1093/beheco/arv029)

2

(1)

(1)

5

6




\section{Figure 1.}

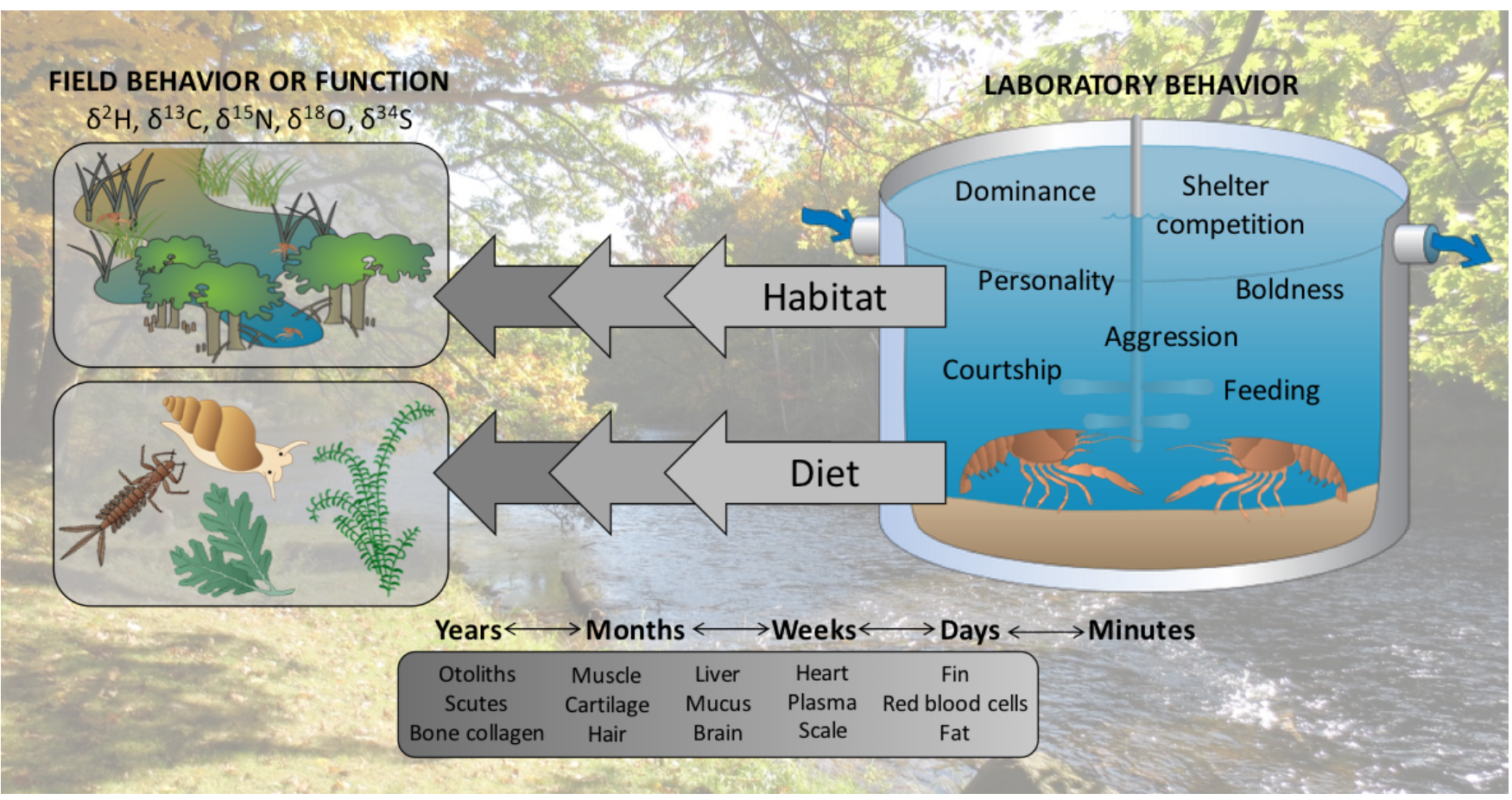

455 Figure 1. Stable isotopes could permit researchers to hindcast the ecological interactions of

456 organisms, linking behaviors observed in the laboratory with previous field function or behavior.

457 Symbols courtesy of the Integration and Application Network (ian.umces.edu/symbols/).

458 Background image is of the study location where organisms were collected (Chippewa River). 


\section{Figure 2.}

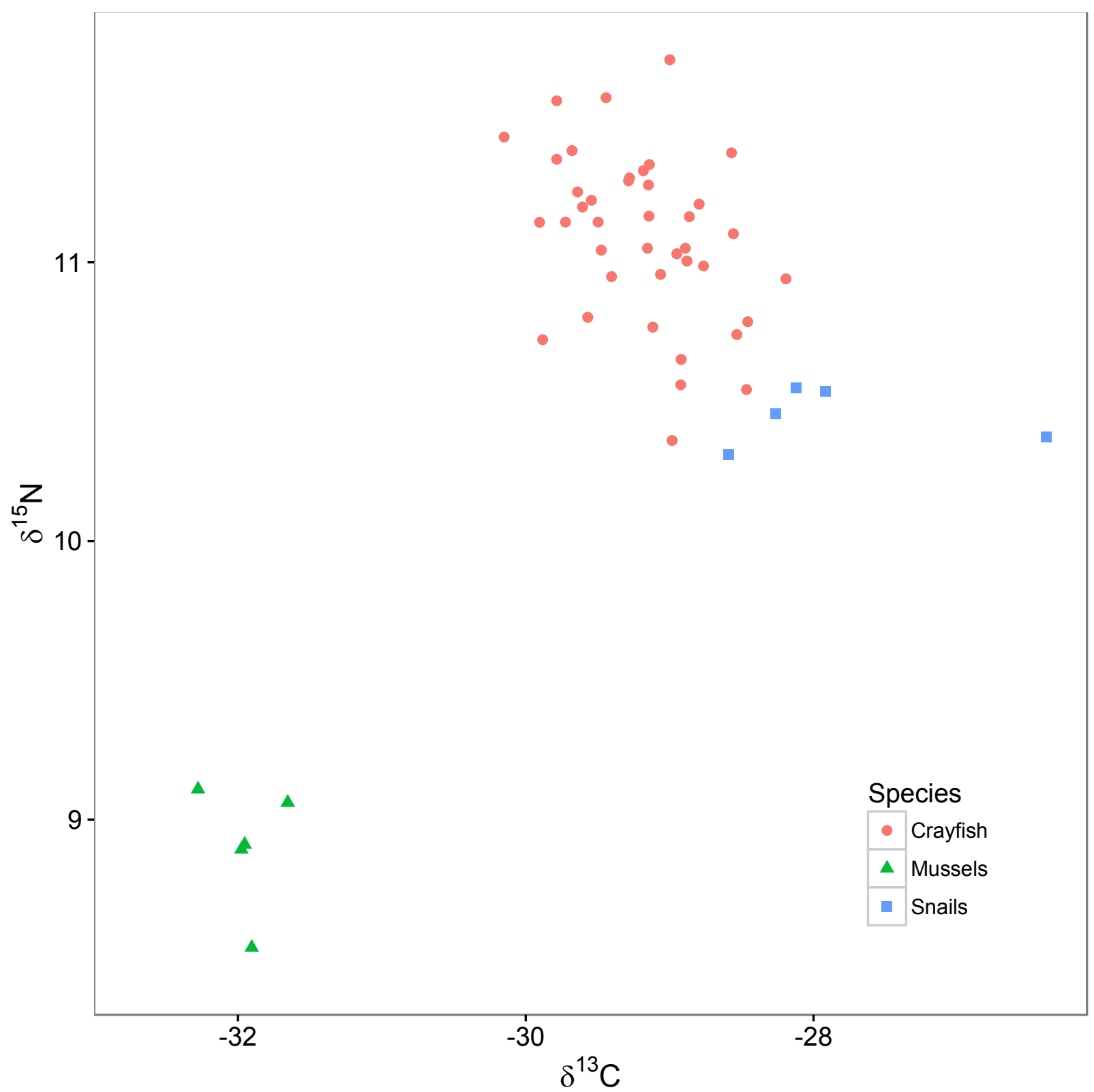

469 Figure 2. Isotopic biplot of $\delta^{13} \mathrm{C}$ and $\delta^{15} \mathrm{~N}$ for crayfish (red circles), mussels (green triangles), 470 and snails (blue squares). All values are expressed in per mille (\%o) relative to a standard of V471 PDB (Vienna PeeDee Belemnite) for carbon and air for nitrogen. 
474 Figure 3.

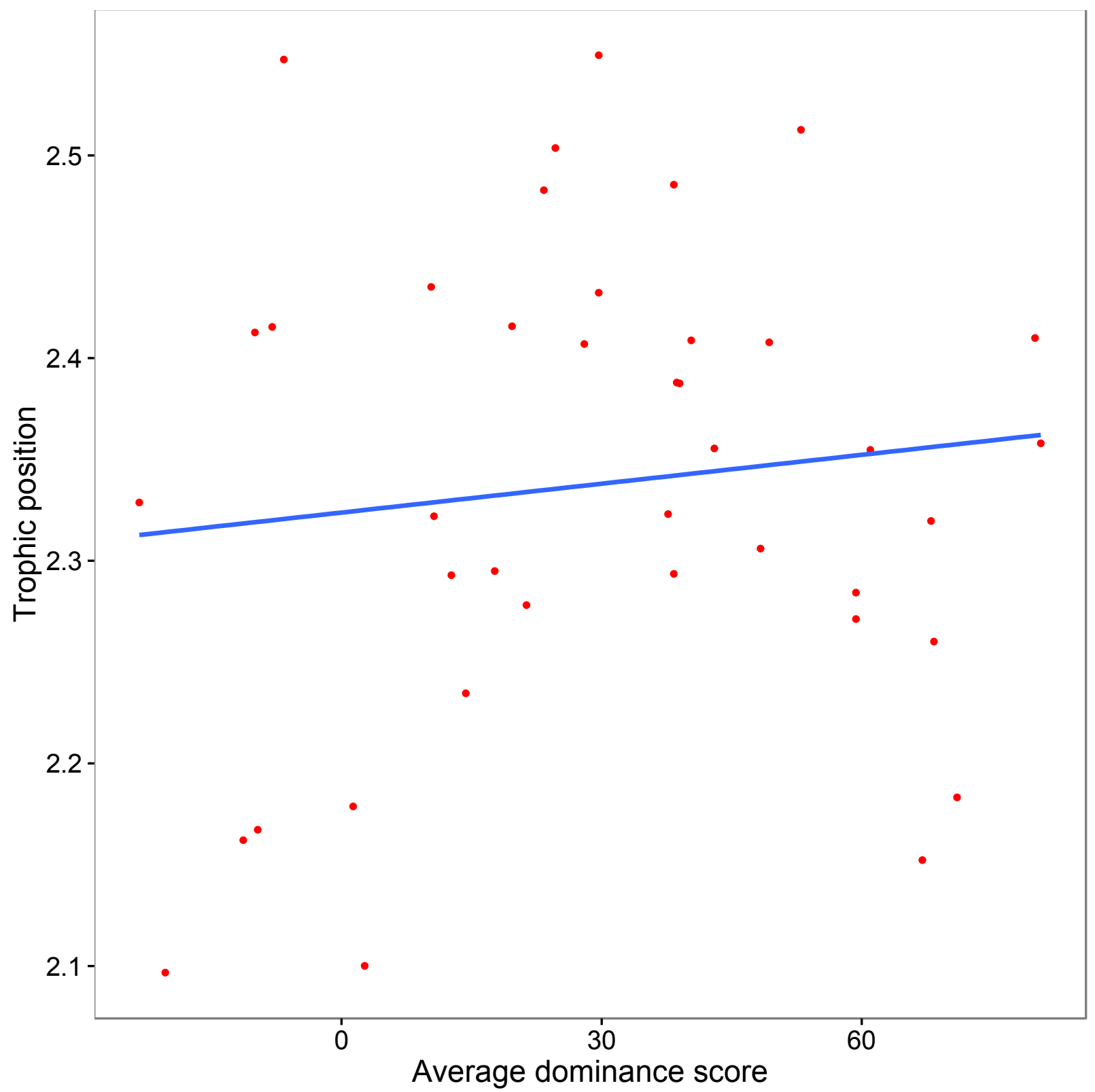

476 Figure 3. Scatterplot (with 95\% CI) of mean assay dominance score for each crayfish over three

477 agonistic assays and in situ trophic position $\left(\mathrm{y}=0.0005 \mathrm{x}+2.32, \mathrm{R}^{2}=0.013, \mathrm{~F}_{1,38}=0.51, p=\right.$ 478 0.48).

479

480 
Table 1. Ethogram modified from Bruski \& Dunham (1987)

\begin{tabular}{cl}
\hline Score & \multicolumn{1}{c}{ Description } \\
\hline-2 & Tail flip or fast retreat \\
-1 & Slow retreat \\
0 & Within one body length with no visible interaction \\
1 & Approach without threat display \\
2 & Approach with threat display (e.g., meral spread, antennal whips) \\
3 & Boxing, pushing, or other agonistic interaction with closed chelae \\
4 & Grabbing, tearing, or other agonistic interaction with opened chelae \\
5 & Full out, unrestrained fighting, usually with interlocked chelae \\
\hline
\end{tabular}

481

482

483

484

485

486

487

488

489

490

491

492

493

494

495

496

497

498 
499 Supplementary material for "Connecting Laboratory Behavior to Field Function through

500 Stable Isotope Analysis"

501

502 Page Content

$50326 \quad$ I. Crayfish morphometrics

$50427 \quad$ Table S1. Crayfish Morphometrics

50528 II. Alternative comparisons of dominance and trophic position

$50631 \quad$ Figure S1. Scatterplot of crayfish carapace length and dominance scores

$50732 \quad$ Figure S2. Scatterplot of the residuals from dominance scores and

508 carapace length regression and calculated trophic position

$50933 \quad$ Figure S3. Scatterplot of crayfish dominance scores and $\delta^{15} \mathrm{~N}$ signatures

51034 III. Analysis of the relationship between percent reliance of crayfish on the snail primary

$511 \quad$ production pathway and dominance

$51236 \quad$ Figure S4. Scatterplot of crayfish dominance scores and percent reliance on snail

$513 \quad$ primary production

$51437 \quad$ IV. References

515

516

517

518

519

520

521 


\section{I. Crayfish morphometrics}

523 Size influences the outcome of crayfish agonistic trials (Rubenstein \& Hazlett, 1974;

524 Bergman \& Moore, 2003); therefore, to better understand what intrinsic factors might be

525 affecting the results of our agonistic assays, we used digital calipers to measure carapace length

526 (CL; from the tip of the rostrum to the posterior edge of the carapace), chelae width (at the

527 widest point of the palm), and chelae length (from the attachment of the carpus and the propodus

528 to the most distal point of the fixed finger) to the nearest hundredth of a mm. We used a digital

529 balance to measure mass to the nearest hundredth of a gram (Table S1). Prior to weighing, we

530 dabbed all crayfish dry for 10 seconds with a paper towel.

531

532

533

534

535

536

537

538

539

540

541

542

543

544 
Table S1. Crayfish morphometrics.

\begin{tabular}{ccccc}
\hline Measurement & Mean & $\begin{array}{c}\text { Standard } \\
\text { Deviation }\end{array}$ & Minimum & Maximum \\
\hline $\begin{array}{c}\text { Carapace length } \\
(\text { mm) }\end{array}$ & 25.38 & 1.26 & 23.41 & 27.53 \\
$\begin{array}{c}\text { Chelae length } \\
(\text { mm) }\end{array}$ & 17.38 & 1.70 & 14.05 & 21.36 \\
$\begin{array}{c}\text { Chelae width } \\
(\mathrm{mm})\end{array}$ & 7.20 & 0.85 & 5.02 & 8.31 \\
Mass (g) & 5.06 & 0.78 & 3.7 & 6.5 \\
\hline
\end{tabular}

545

546

547

548

549

550

551

552

553

554

555

556

557

558

559

560

561

562 
563 II. Alternative comparisons of dominance and trophic position

564 Body size is a factor that strongly influences the outcome of agonistic encounters in

565 crayfish, with larger individuals generally being more dominant (Bovbjerg, 1953; Rubenstein \&

566 Hazlett, 1974; Bergman \& Moore, 2003). We used as small of a crayfish size range as

567 logistically possible, but the difference between our largest and smallest study organisms was

568 still $4.12 \mathrm{~mm}$ carapace length (Table S1). Despite this, most paired agonistic interaction trials

569 were between more closely size-matched crayfish (mean \pm standard deviation; $1.44 \pm 1.15 \mathrm{~mm}$

570 carapace length). Regardless, we sought to determine if dominance scores might better

571 correspond with the trophic positions of our crayfish if we corrected for the role of size

572 differences in determining outcomes of agonistic interactions. We did not correct for potential

573 ontogenetic effects of crayfish size on trophic position (Bondar et al., 2005; Larson, Olden \&

574 Usio, 2010), because we found no significant relationship between crayfish carapace length

575 (Table S1) and trophic position $\left(\mathrm{y}=0.002 \mathrm{x}+2.27, \mathrm{R}^{2}=0.001, \mathrm{~F}_{1,38}=0.02, \mathrm{p}=0.88\right)$. However,

576 as we anticipated, there was a significant relationship between crayfish carapace length and mean

577 dominance score $\left(y=11.503 x-261.971, R^{2}=0.26, F_{1,38}=13.03, p<0.001\right.$; Figure S1). Yet,

578 when we corrected for the effect of crayfish size on dominance by regressing residuals of the

579 preceding analysis against trophic position, we still did not find a significant relationship,

580 consistent with our main text conclusion $\left(y=0.00 x+2.34, R^{2}=0.01, F_{1,38}=0.54, p=0.47\right.$;

581 Figure S2). The lack of a relationship between dominance and trophic position is therefore

582 conserved even when accounting for the potential influence of crayfish size on dominance.

583 Carapace length is the most commonly used size metric for crayfish; however, chelae size

584 has been shown to dictate success in agonistic encounters and may be a better measure of

585 dominance in crayfish (Garvey \& Stein, 1993). We therefore ran two additional iterations of the 
586 analysis presented above, using chelae length and width instead of carapace length. We found 587 significant relationships between mean dominance scores and both chelae length $(y=9.125 x-$ $\left.588128.686, \mathrm{R}^{2}=0.29, \mathrm{~F}_{1,38}=15.72, \mathrm{p}<0.001\right)$ and chelae width $\left(\mathrm{y}=16.040 \mathrm{x}-85.562, \mathrm{R}^{2}=0.23\right.$, $\left.589 \mathrm{~F}_{1,38}=11.07, \mathrm{p}=0.002\right)$. Yet again, regressing residuals from the chelae length or width and 590 dominance score analyses against trophic position did not change our main text conclusion that 591 that dominance and trophic position are unrelated (chelae length residuals vs trophic position: $y$ $592=0.0002 \mathrm{x}-2.34, \mathrm{R}^{2}=0.001, \mathrm{~F}_{1,38}=0.04, \mathrm{p}=0.85$; chelae width residuals vs trophic position: $\mathrm{y}$ $\left.593=-0.0001 x-2.34, \mathrm{R}^{2}=0.01, \mathrm{~F}_{1,38}=0.02, \mathrm{p}=0.89\right)$.

594 The use of isotopic mixing models, applied here as a step in calculating trophic position 595 (Post, 2002), is dependent on a number of assumptions. For example, stream and river 596 ecosystems can have extremely high spatiotemporal variation in the $\delta^{13} \mathrm{C}$ and $\delta^{15} \mathrm{~N}$ values of 597 sources of primary production owing to a number of factors (Fry \& Sherr, 1984; Finlay, 2001;

598 Trudeau \& Rasmussen, 2003). Accordingly, we followed convention in using primary consumers 599 rather than primary producers in mixing model calculations of trophic position, as long-lived 600 organisms like mussels or snails can integrate and correct for this variability (Post, 2002; Cabana $601 \&$ Rasmussen, 1996). However, we cannot exclude that our field sampling of primary consumer 602 endpoints for our mixing model could have missed some such variability inherent to 603 heterogeneous lotic ecosystems, and our collection of potential prey resources concurrent with 604 crayfish consumers does not necessarily reflect isotopic values of prey items for Orconectes 605 rusticus over preceding weeks or months (Moore \& Semmens, 2008). Another assumption of 606 mixing models is that constant discrimination factors can be used for each trophic step and 607 between different taxonomic groups and diet items. However, discrimination factors can vary 608 across taxa, diets, and tissues used (e.g., Stenroth et al., 2006; Caut, Angulo \& Courchamp, 
609 2009; Phillips et al., 2014), and consequently may misrepresent trophic position of a focal 610 organism (Bond \& Diamond, 2011). Due to the potential vulnerability of our model to the 611 preceding assumptions, we also conducted a simpler analysis using crayfish dominance scores

612 and unaltered $\delta^{15} \mathrm{~N}$ values to determine if our results were dependent on our specific trophic

613 position calculations. Doing so did not alter our overall nonsignificant result and conclusion $(\mathrm{y}=$

$6140.002 x+11.04, R^{2}=0.03, F_{1,38}=1.29, p=0.26$; Figure S3). We therefore conclude that our

615 result of a lack of relationship between crayfish dominance in the laboratory and trophic position

616 in the field is robust to our measures of both crayfish dominance and trophic position.

617

618

619

620

621

622

623

624

625

626

627

628

629

630

631 


\section{Figure S1.}

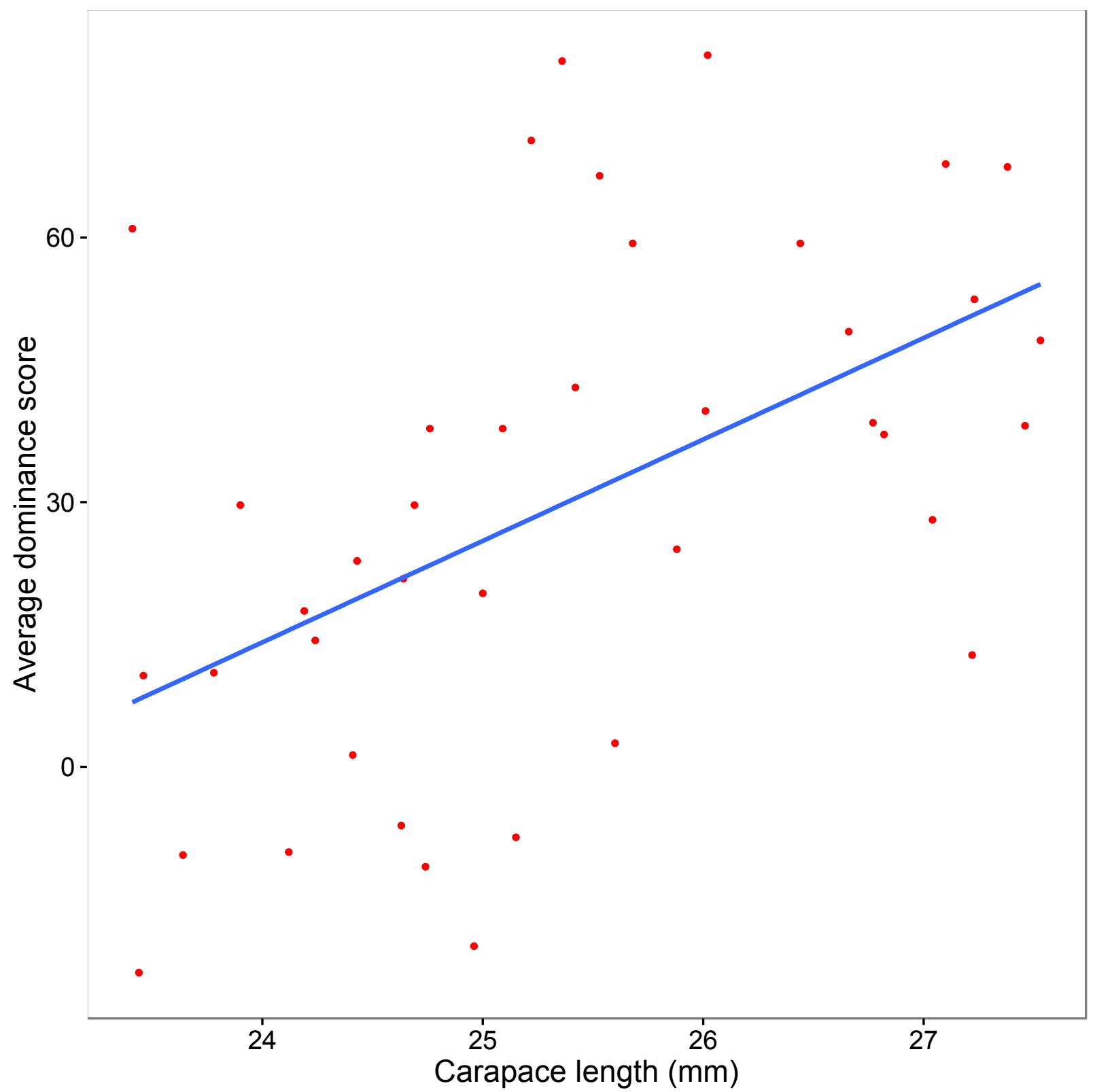

633

634 Figure S1. Scatterplot (with 95\% CI) showing significant relationship between crayfish carapace

635 length and dominance score from behavioral assays $\left(\mathrm{y}=11.503 \mathrm{x}-261.971, \mathrm{R}^{2}=0.26, \mathrm{~F}_{1,38}=\right.$

$63613.03, \mathrm{p}<0.001)$.

637

638 
639 Figure S2.

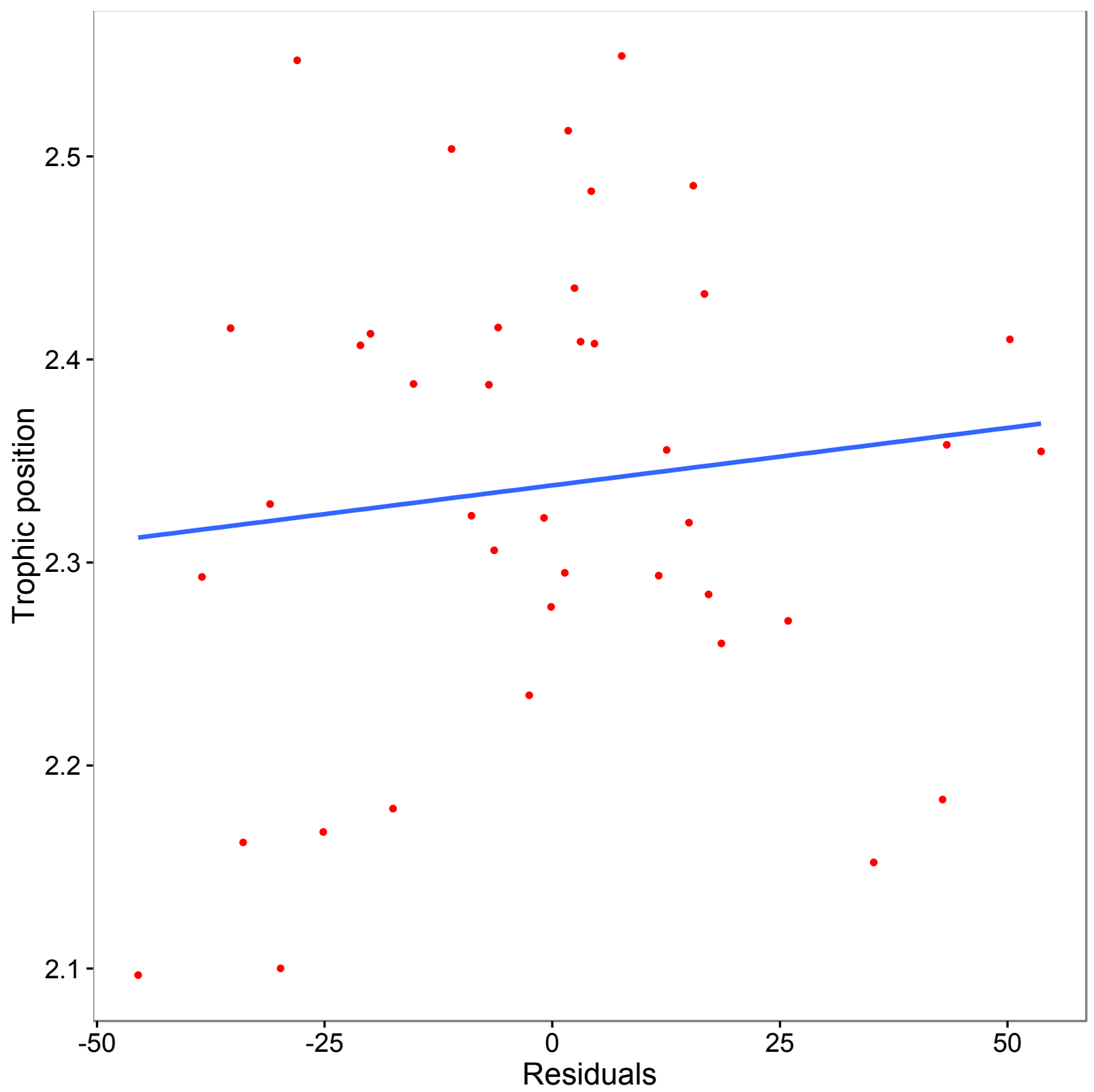

640

641 Figure S2. Scatterplot (with 95\% CI) of the residuals from crayfish dominance and carapace

642 length regression against calculated trophic position $\left(\mathrm{y}=0.001 \mathrm{x}+2.34, \mathrm{R}^{2}=0.01, \mathrm{~F}_{1,38}=0.54, \mathrm{p}\right.$ $643=0.47)$

644

645 


\section{Figure S3.}

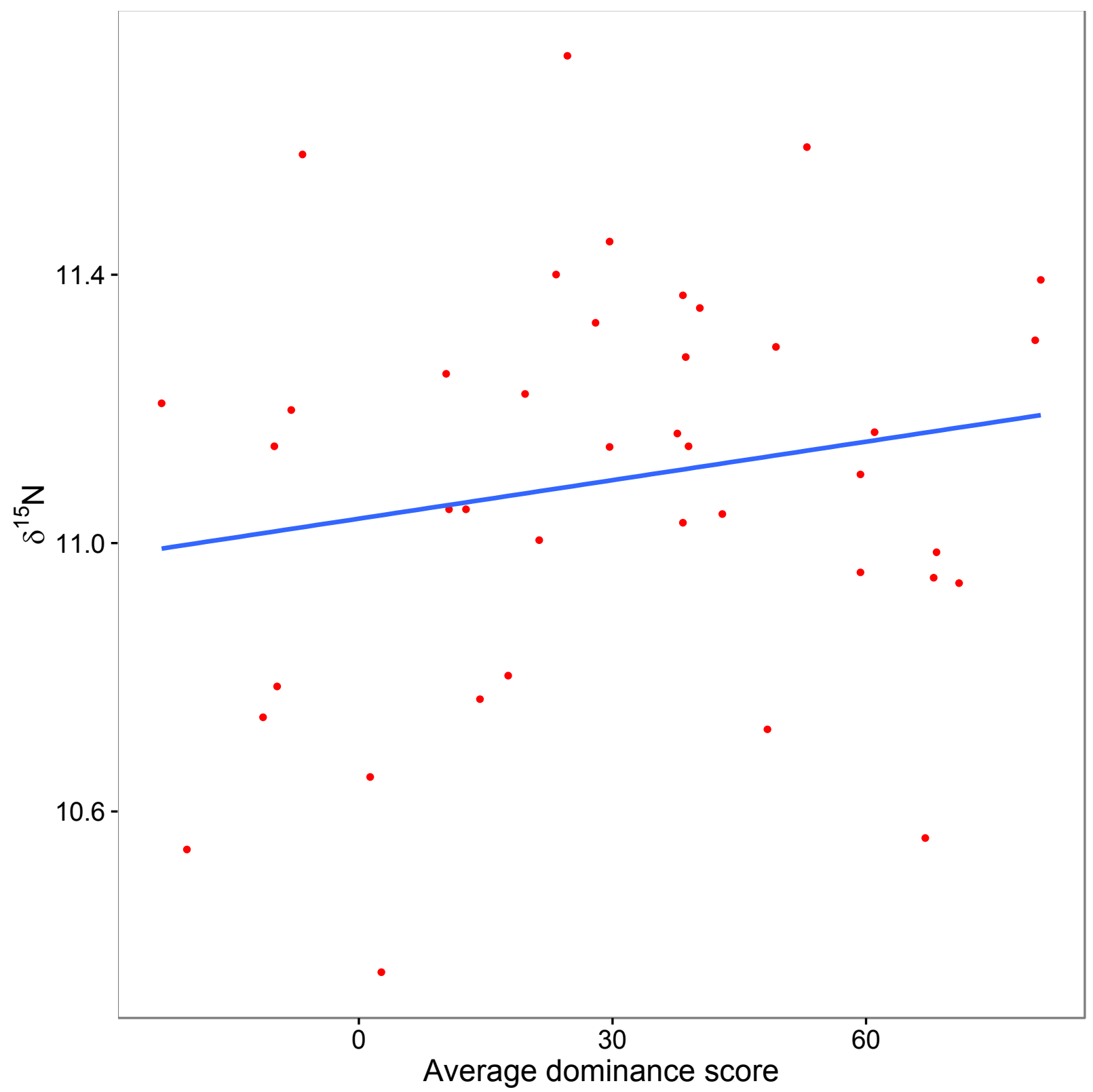

648 Figure S3. Scatterplot (with 95\% CI) of crayfish dominance scores and $\delta^{15} \mathrm{~N}$ signatures $(\mathrm{y}=$

$\left.6490.002 x+11.04, R^{2}=0.03, F_{1,38}=1.29, p=0.26\right)$

650

651

652 
653 III. Analysis of the relationship between percent reliance of crayfish on the snail primary

654 production pathway and dominance

655 Our mixing model calculations revealed variation in the percent reliance of $O$. rusticus

656 from the Chippewa River on food resources represented by the two primary consumer endpoints

657 used in our study. Specifically, crayfish relied more on the isotopically-enriched primary

658 production represented by snails (mean \pm standard deviation, $67.6 \pm 11.3 \%$ ) than on the

659 isotopically-depleted primary production represented by mussels (32.4 $\pm 11.3 \%$; Figure 2$)$. In

660 lotic systems, the isotopic values of freshwater mussels generally reflect those of a broad range

661 of potential sources of primary production including terrestrial detritus and phytoplankton from

662 upstream lentic systems (Raikow \& Hamilton, 2001; Cole \& Solomon, 2002). Therefore,

663 reliance of our crayfish on the mussel endpoint may reflect dependence of $O$. rusticus on

664 terrestrial detritus, in part because we do not anticipate high reliance of crayfish on

665 phytoplankton (Stenroth et al., 2006). Conversely, reliance of O. rusticus on snails likely

666 represents use of benthic algae as a basal resource, particularly given the generally low trophic

667 positions of the crayfish in our study. Benthic algae or other autochthonous production in

668 freshwater ecosystems may be a higher quality diet item than terrestrial detritus (Finlay, 2001;

669 Brett et al., 2009), and consequently, we hypothesized that more dominant crayfish in our

670 behavioral assays might show greater dependence on algal or snail resources than the alternative

671 resources represented by freshwater mussels. In order to test this hypothesis, we ran a regression

672 between percent reliance on the snail endpoint of our mixing model and our dominance assay

673 scores, as previously analyzed for trophic position (see main text and above). Again, we did not

674 find a significant relationship between crayfish dominance and diet $\left(\mathrm{y}=0.02 \mathrm{x}+66.98, \mathrm{R}^{2}=\right.$

$6750.002, \mathrm{~F}_{1,38}=0.09, p=0.76$; Figure $\mathrm{S} 4$ ), further supporting our conclusion that results of ex situ 
676 laboratory behavioral trials do not necessarily translate to the hindcasted in situ ecology of these

677 same individual organisms.

678

679

680

681

682

683

684

685

686

687

688

689

690

691

692

693

694

695

696

697

698 
699 Figure S4.

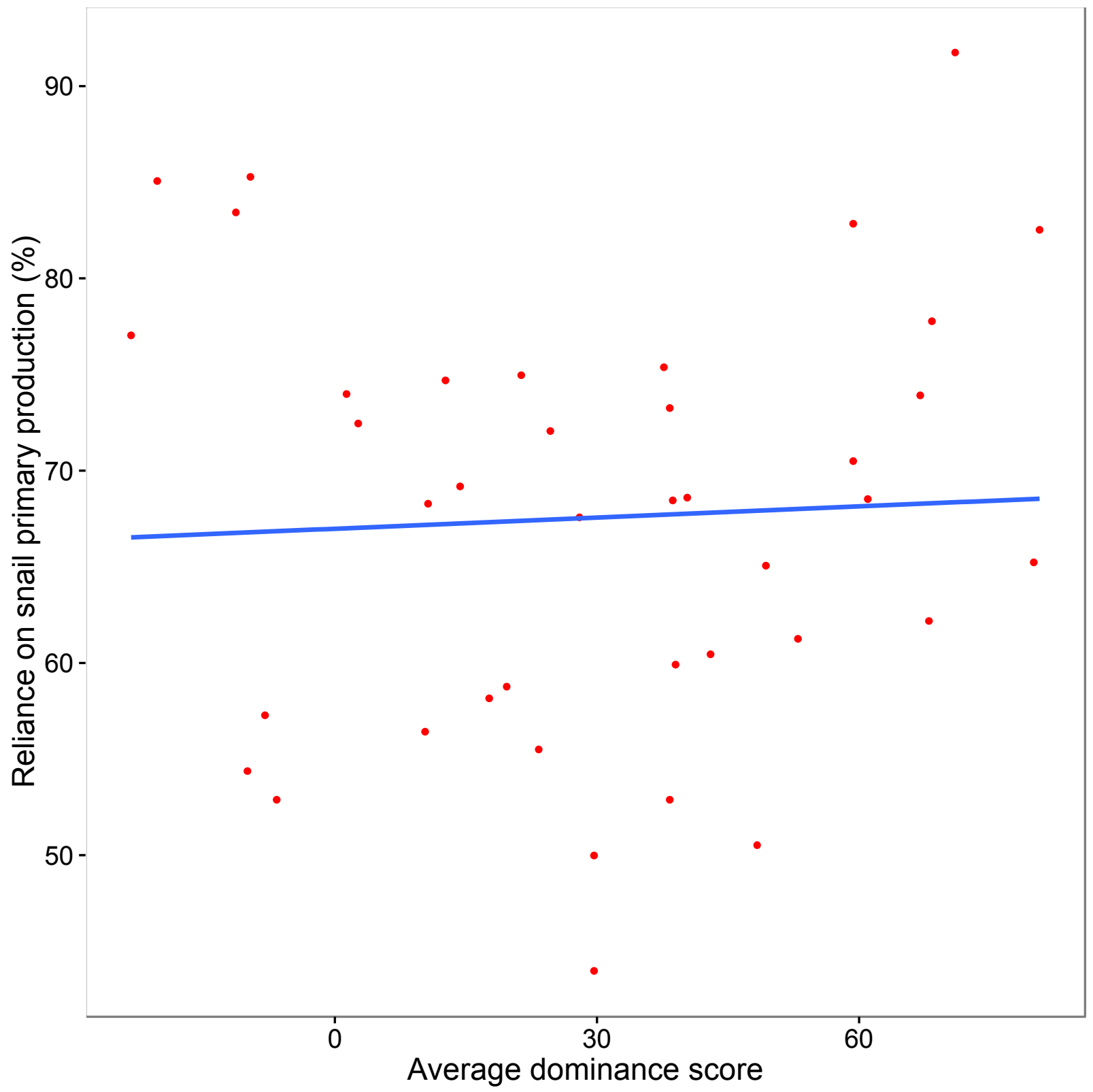

701 Figure S4. Scatterplot (with 95\% CI) of mean assay dominance score for each crayfish over

702 three agonistic assays and percent reliance on the snail primary production pathway $(\mathrm{y}=0.02 \mathrm{x}+$ $\left.70366.98, \mathrm{R}^{2}=0.002, \mathrm{~F}_{1,38}=0.09, p=0.76\right)$.

704 
706

707

708

709

710

711

712

713

714

715

716

717

718

719

720

721

722

723

724

725

726

727

728

\section{References}

1. Bergman DA, Moore PA. 2003 Field observations of intraspecific agonistic behavior of two crayfish species. The Biological Bulletin 205, 26-35. (doi:10.2307/1543442)

2. Bond AL, Diamond AW. 2011 Recent Bayesian stable-isotope mixing models are highly sensitive to variation in discrimination factors. Ecological Applications 21, 1017-1023.

3. Bondar CA, Bottriell K, Zeron K, Richardson JS. 2005 Does trophic position of the omnivorous signal crayfish (Pacifastacus leniusculus) in a stream food web vary with life history stage or density? Canadian Journal of Fisheries and Aquatic Sciences 62, 26322639. (doi: 10.1139/f05-167)

4. Bovbjerg RV. 1953 Dominance order in the Crayfish Orconectes virilis (Hagen). Physiological Zoology 26, 173-178.

5. Brett MT, Kainz MJ, Taipale SJ, Seshan H. 2009 Phytoplankton, not allochthonous carbon, sustains herbivorous zooplankton production. Proceedings of the National Academy of Sciences of the United States of America 106, 21197-21201.

6. Cabana G, Rasmussen JB. 1996 Comparison of aquatic food chains using nitrogen isotopes. Proceedings of the National Academy of Sciences of the United States of America 93, 10844-10847.

7. Caut S, Angulo E, Courchamp F. 2009. Variation in discrimination factors $\left(\Delta^{15} \mathrm{~N}\right.$ and $\left.\Delta^{13} \mathrm{C}\right)$ : the effect of diet isotopic values and applications for diet reconstruction. Journal of Applied Ecology 46, 443-453. (doi:10.1111/j.1365-2664.2009.01620.x)

8. Cole JJ, Solomon CT. 2012 Terrestrial support of zebra mussels and the Hudson River food web: A multi-isotope, Bayesian analysis. Limnology and Oceanography. 57, 18021815. (doi:10.4319/1o.2012.57.6.1802) 
729 9. Finlay JC. 2001 Stable-carbon-isotope ratios of river biota: implications for energy flow

$730 \quad$ in lotic food webs. Ecology 82, 1052-1064.(doi:10.1890/0012-

731 9658(2001)082[1052:SCIROR]2.0.CO;2)

732 10. Fry B, Sherr EB. $1984 \Delta^{13} \mathrm{C}$ measurements as indicators of carbon flow in marine and 733 freshwater ecosystems. Contributions in Marine Science 27, 13-47.

$734 \quad$ (doi:10.1007\%2F978-1-4612-3498-2_12)

735 11. Garvey JE, Stein RA. 1993 Evaluating how chela size influences the invasion potential of an introduced crayfish (Orconectes rusticus). The American Midland Naturalist 129, 172181. (doi:10.2307/2426446)

12. Larson ER, Olden JD, Usio N. 2010 Decoupled conservatism of Grinnellian and Eltonian niches in an invasive arthropod. Ecosphere 1, 1-13. (doi: http://10.1890/ES10-00053.1)

13. Moore JW, Semmens BX. 2008 Incorporating uncertainty and prior information into stable isotope mixing models. Nature 11, 470-480. (doi:10.1111/j.14610248.2008.01163.x)

14. Phillips DL, Inger R, Bearhop S, Jackson AL, Moore JW, Parnell AC, Semmens BX, Ward EJ. 2014 Best practices for use of stable isotope mixing models in food web studies. Canadian Journal of Zoology 92, 823-835. (doi: http://10.1139/cjz-2014-0127)

15. Post DM. 2002 Using stable isotopes to estimate trophic position: models, methods, and assumptions. Ecology 83, 703-718. (doi:10.1890/00129658(2002)083[0703:USITET]2.0.CO;2)

16. Raikow DF, Hamilton SK. 2001 Bivalve diets in a Midwestern U.S. stream: A stable isotope enrichment study. Limnology and Oceanography 46, 514-422. (doi:10.4319/1o.2001.46.3.0514) 
752 17. Roth BM, Hein CL, Vander Zanden MJ. 2006 Using bioenergetics and stable isotopes to 753 assess the trophic role of rusty crayfish (Orconectes rusticus) in lake littoral zones.

754 Canadian Journal of Fisheries and Aquatic Sciences 63, 335-344. (doi:10.1139/f05-217)

755 18. Rubenstein DI, Hazlett BA. 1974 Examination of the agonistic behavior of the crayfish

756 Orconectes virilis by character analysis. Behavior 50, 193-216.

757 (doi:10.2307/4533609?ref=no-X-route:1dae0e260ae10f0d6415e334220ef8a2)

758 19. Stenroth P, Homqvist N, Nyström P, Berglund O, Larsson P, Granéli W. 2006 Stable

759 isotopes as an indicator of diet in omnivorous crayfish (Pacifastacus leniusculus): the

760 influence of tissue, sample treatment, and season. Canadian Journal of Fisheries and

$761 \quad$ Aquatic Sciences 63, 821-831. (doi:10.1139/f05-265)

762 20. Trudeau V, Rasmussen JB. 2003 The effect of water velocity on stable carbon and

763 nitrogen isotope signatures of periphyton. Limnology and Oceanography 48, 2194-2199.

$764 \quad$ (doi:10.4319/1o.2003.48.6.2194) 